НАУКИ О ЗЕМЛЕ

"НАУКА. ИННОВАЦИИ. ТЕХНОЛОГИИ", № 3, 2019

25.00 .24

УДК $913(332.14)$

Рубанов И.Н. Нокелайнен Т.С., Калинкин И.В. Игонин А.И.,

Введение:

Материалы и методы:

Результаты:

Выводы:

Ключевые слова:
ЭКОНОМИЧЕСКАЯ, СОЦИАЛЬНАЯ,

ПОЛИТИЧЕСКАЯ И РЕКРЕАЦИОННАЯ ГЕОГРАФИЯ

rubanovin@yandex.ru

nokelta@rambler.ru

ikl@geogr.msu.su

geoigonin@gmail.com

МГУ им. М.В. Ломоносова, г. Москва, Россия

\section{ИСПОЛЬЗОВАНИЕ ОФИЦИАЛЬНЫХ СТАТИСТИЧЕСКИХ ПОКАЗАТЕЛЕЙ ДЛЯ ОЦЕНКИ СТЕПЕНИ УСТОЙЧИВОСТИ ЭКОНОМИЧЕСКОГО РАЗВИТИЯ РЕГИОНОВ РОССИИ}

в качестве основной стратегии долгосрочного гармоничного развития общества в России и мире признана концепция устойчивого развития, которая подразумевает одновременное достижение социальной, экономической и экологической устойчивости. Оценка степени устойчивости актуальна для территорий России поскольку позволяет вскрыть значительные различия между ними обусловленные историко-культурными, социально-экономическими и природными факторами. Наиболее сложной представляется оценка экономической устойчивости, требующая учета экологических последствий хозяйственной деятельности и определение некого «оптимального» уровня производства материальных благ. Автором предложена методика экспресс-оценки экономической устойчивости регионов России на основе общедоступных и регулярно публикуемых статистических показателей.

для оценки экономической устойчивости использовались два интегральных показателя характеризующих качественный и количественный аспекты хозяйственной деятельности. Количественный аспект характеризовался на основе дефлированного показателя душевого ВРП для регионов России. Качественный показатель рассчитывался на основе данных о структуре экономики по видам экономической деятельности и структуре промышленного производства - на основе экспертной оценки и статистических данных вычленялась доля ВРП связанная с эксплуатацией невозобновляемых природных ресурсов и значительным ущербом окружающей среде.

в 2017 около половины валового регионального продукта регионов России связаны с эксплуатацией невозобновляемых ресурсов и отраслями наносящими значительный ущерб окружающей среде. С 2005 года этот показатель не имеет выраженных тенденций к изменению. На фоне его незначительного улучшения в большинстве «несырьевых» регионов, наблюдается значительное ухудшение этого показателя в ряде регионов, где были запущены крупные проекты по добыче полезных ископаемых (Ненецкий а.о., Сахалинская, Астраханская обл. и др.). Показатель ВРП на душу населения в постоянных ценах быстро возрастал с 1999 по 2007 г., с 2012 года наблюдается его стагнация. С 2014 по 2017 г. выраженных изменений показателя не наблюдается, за исключением его существенного роста в двух субъектах присоединенного Крымского полуострова.

успех в структурных изменениях отечественной экономики и снижении ее сырьевой зависимости на интервале с 2005 по 2017 гг. не наблюдается. В рассматриваемый период фиксируется ускоренное развитие восточных регионов страны, которое, однако, в основном связано с расширением эксплуатации природных ресурсов. Значительные изменения душевого ВРП наблюдавшиеся в отдельных регионах за последние с 2007 по 2017 гг. в большинстве случаев связаны с запуском и расширением проектов по добыче полезных ископаемых, реже - с эффективной деятельностью региональных администраций по привлечению частного капитала.

устойчивое развитие, регионы, Россия, социальный, экономический, индикатор 


$\begin{array}{ll}\text { Rubanov I.N., } & \text { rubanovin@yandex.ru } \\ \text { Nokelaynen T.S., } & \text { nokelta@rambler.ru } \\ \text { Kalinkin I.V. } & \text { ikl@geogr.msu.su } \\ \text { Igonin A.I., } & \text { geoigonin@gmail.com } \\ & \text { Lomonosov Moscow State University } \\ & \begin{array}{l}\text { implementation of Official Statistics } \\ \text { for Assessment of Economic Sustainability } \\ \text { of Russian Regions }\end{array}\end{array}$

Introduction: $\quad$ sustainable development is recognized as basics concept for harmonious long-term development in Russia and on the global level. It implies simultaneous achieving social, economic and ecologic sustainability. Assessment of sustainability is actual for territories of Russia as far as it reveals profound differences caused by historic, cultural, social, economic and natural factors. Assessment of economic sustainability looks the most difficult since it needs calculation of ecological externalities and definition of optimum economic production level. The author propose methodology of express-assessment of Russian regions economic sustainability on the base of free and regularly published statistical data.

Materials and methods: two synthetic indicators were used for assessment of quantitative and qualitative aspects of economic sustainability. Quantitative aspects were assessed on the base of per capita regional product deflated data. Qualitative indicator was calculated using data on economy structure and structure of manufacturing - the share of regional product related to exploitation of non-renewable resources and sufficient environment damage was identified on the base of this data and expert assessment.

Results: $\quad$ almost a half of regional product in Russia was related in 2017 to exploitation of non-renewable resources and environmentally threating economy. Corresponding indicator has been oscillating without obvious trend since 2005. While it has slightly improved in most regions of Russia with historically low primary production, it has worsened greatly in some regions where mining projects had been launched (Nenetsky, Sakhalyn, Astrakhan regions and others). Per capita regional product in constant prices had been quickly grown since 1999 until 2007, but it has been stagnating since 2012 . There no pronounce changes of per capita regional products in most regions since 2014 to 2017 . The only exception - it's significant growth in both regions of Crimea.

Conclusion: there no success in turning from commodity dependence for the 2005-2017 period in Russia. Stronger economy growth is observed in Eastern regions but it in most cases relies to intensification of natural resources exploration. Strongest changes of per capita regional product since 2007 to 2017 usually relates to changes in mining industry production and in minor cases it relates to efficient management of regional administrations which succeeded to attract private investment.

Keywords: $\quad$ sustainable development, region, Russia, social, economic, indicators.

\section{ВВЕДЕНИЕ}

В последние 50 лет в качестве наиболее эффективного и гармоничного подхода к долгосрочному развитию общества признана концепция устойчивого развития (англ. - sustainable development). В 1980-е годы этот подход был зафиксирована в качестве приоритетного в программных документах ООН и ее подразделений [1]. В 1996 году указом Президента Российской Федерации концепция устойчивого развития принята в 
качестве стратегии развития нашей страны [2]. Традиционно исследователи выделяют три основные компоненты устойчивого развития, которые должны достигаться одновременно - экологическую, социальную и экономическую [3].

Для России актуальная оценка интегральной устойчивости развития отдельных территорий и их успеха в достижении отдельных ее составляющих. Из-за значительных пространственных различий обусловленных природными, историческими и социально-экономическими факторами данные оценки имеют принщипиальное значение для региональной политики, учета территориальной специфики при разработке законодательных актов и федеральных программ социально-экономического развития.

Особенно сложной представляется оценка экономической составляющей устойчивости. С точки зрения устойчивого развития обязательным становится учет экологических последствий экономической деятельности и сопутствуюшего ущерба окружающей среде (т.н. «зеленые счета» [4]), оценка которого представляется сложной субъективной задачей и российскими официальными органами не ведется. В частности, для этих целей необходимо оценивать т.н. природный капитал, который включает не толыко оценку стоимости минеральных ресурсов, но и стоимостную оценку среды обитания человека и ее качественных характеристик, а также изменение этой величины. С учетом описанного подхода экономический рост и экономическая деятельность в разных секторах экономики должна оцениваться по разному. В частности, экономическая деятельность основанная на эксплуатации исчерпаемых природных ресурсов по определению не может считаться устойчивой, в отличие от деятельности базирующейся на эксплуатации человеческого капитала, который может быть возобновлен [4].

В отличие от большинства других индикаторов, однонаправленное изменение показателей производства товаров и услуг, и даже рост благосостояния не могут трактоваться однозначно. Поскольку удовлетворения базовых (вода, еда, жилище) и других значимых (саморазвитие) потребностей индивида требует конечное количество ресурсов и финансовых затрат целесообразным оказывается некий конечный уровень материального производства и использования природных ресурсов, вместо его бесконечного роста [6]. Оценка экономической устойчивости и благосостояния населения требует ответов на философские вопросы. Является ли материальное благополучие обязательным атрибутом устойчивого общества и каков его оптимальный уровень?

В представленной работе предложена оригинальная методика экспресс-оценки экономической устойчивости на основе официальных статистических показателей регулярно рассчитываемых и публикуемых Федеральными органами власти России. Проведен качественный, количественный анализ экономических показателей, их пространственная дифференциация и динамика. 
Предложенная автором методология не претендует на полноту и предельную точность качественных оценок, в частности, она не учитывает всех нюансов расчета «зеленых счетов», а также возможные вариации и тенденции изменения экологической эффективности в отдельных секторах экономической деятельности. В то же время приведенный анализ обладает низкой степенью субъективности, позволяет проводить динамические и пространственные сопоставления показателей экономического развития территорий России на основе достоверных и легкодоступных данных, а также дает количественную оценку некоторым малоизученным феноменам экономического развития страны.

\section{МАТЕРИАЛЫ И МЕТОДЫ}

Для экспресс оценки экономической устойчивости развития российских регионов автором использовались интегральные индикаторы - синтетические величины оцениваемые на основе нескольких статистических показателей [10]. Экономическая устойчивость оценивалась по двум критериям - качественному и количественному.

Количественный индикатор призван отразить объем производства благ (в стоимостном выражении) и таким образом характеризуют возможности общества удовлетворять текущие потребности в товарах и услугах. Главным статистическим показателем такого рода традиционно считается валовый региональный продукт в расчете на душу населения. Для того, чтобы можно было сопоставлять данные разных лет, этот показатель дефлировался путем корректировки на величину накопленной инфляции, те. рассчитан в постоянных ценах (в качестве базового принят 2012 г.).

Уровень душевого производства в Российской Федерации остается низким (по мировым меркам и в сравнении с принятыми критериями оценки уровня богатства). Так в рамках оценки индекса развития человеческого потенциала, одобренной $\mathrm{OOH}$, в качестве верхнего порога материального богатства рассматривается уровень душевого ВВП равный 75 тыс. долл. США в год, в то время как в России эта величина в 2017 году составила лишь 11,3 тыс. долл. США [12, 8]. В Российской Федерации в ретроспективе и ближайшей перспективе на наш взгляд приемлемо позитивно оценивать высокие показатели валового производства и их рост сам по себе, без учета проблемы определения некого оптимального значения показателя.

Экологические последствия экономической деятельности и устойчивость экономики оценивались с помошью качественного индикатора (далее «качество экономики»). Последний рассчитывался на основе структурных показателей (структура производства по отраслям и подотраслям экономики) - путем определения веса отраслей связанных с эксплуатацией невозобновляемых ресурсов (добыча полезных ископаемых), и (или) деятельность которых сопряжена с значительным ущербом окружающей среде. Качествен- 
ный (с этой точки зрения) характер каждого из секторов экономики определялся авторами экспертно.

Из общего объема произведённого в регионе добавленного продукта принимаемого за $100 \%$, в рамках такого анализа в несколько этапов проводилось вычитание части производств отдельных отраслей. Во-первых, полностью вычиталась доля сектора добычи полезных ископаемых; а также доли некоторых подотраслей обрабатывающей промышленности отличающихся особенно значительным негативным воздействием на окружающую среду, а именно: целлюлозно-бумажное производство, производство кокса и нефтепродуктов, химическое производство, металлургия. Во-вторых, вычиталась половина объема производства секторов экономики наносящих умеренный вред окружающей среде, в числе которых сельское хозяйство, рыболовство, транспорт и связь, а также подотрасли промышленности: производство пищевых продуктов, обработка древесины, производство резиновых и пластмассовых изделий, производство неметаллических продуктов. В-третьих, автор исходил из того, что добыча полезных ископаемых косвенно (через налоговые поступления в региональный бюджет, заработную плату, спрос на товары и услуги), стимулирует производство в таких секторах как строительство, оптовая и розничная торговля, транспорт и связь, финансовая деятельность. По этой причине мы также вычитали из общего объема производства часть производства в этих секторах пропорциональную роли добывающей промышленности в ВРП региона (например, если вес добывающей промышленности в ВРП составляет $10 \%$, вычиталась одна десятая часть производства этих отраслей).

В результате упомянутой последовательности действий для каждого из регионов рассчитывался показатель «качества экономики», который теоретически может варьировать в диапазоне от $0 \%$ (вся хозяйственная деятельность представлена производствами наносящими серьезный урон окружающей среде) до 100\% («грязные» производства отсутствуют).

Для расчетов использовались официальные статистические данные Росстата за 1990-2017 годы, представленные в электронной базе данных ЕМИСС [12] в виде следующих показателей/таблиц

- $\quad$ среднегодовая численность населения по субъектам,
валовый региональный продукт на душу населения по субъ-
ектам;
потребительская инфляция средняя за год;
- $\quad$ отраслевая структура валовой добавленной стоимости
субъектов (таблица);
структура объема отгруженной продукции (работ, услуг) по
виду экономической деятельности “Обрабатывающие про-
изводства” по субъектам (таблица).




\section{РЕЗУЛЬТАТЫ ИССЛЕДОВАНИЯ}

\section{Качественная оценка}

В 2017 году в целом по России индекс «качества экономики〉 составил $57 \%$. Косвенно данную величину можно интерпретировать следующим образом - около $43 \%$ валовой добавленной стоимости формируемой внутри страны прямо или косвенно тесно связаны с использованием невозобновляемых ресурсов, их первичной переработкой, производствами, наносящими значительный ущерб окружающей среде. Роль ресурсных секторов в экономике России следует признать умеренно высокой по мировым меркам. Этот вывод коррелирует с данными Мирового банка, который ежегодно оценивает роль в экономике ренты от добычи природных ресурсов, которая представляет собой разницу между стоимостью реализации добытых полезных ископаемых и лесных ресурсов по рыночным ценам и их полной себестоимостью. В соответствии с данными Мирового банка размер природной ренты (анал. natural resources rent, рассчитываемый на основе стоимости использованных лесных ресурсов и полезных ископаемых) в России в 2013 г. составила $10,7 \%$ ВВП, а в целом по странам мира - 2,2\% ВВП; по величине показателя страна заняла 51 место из 226 стран и территорий [8].

Данные Мирового банка указывают на позитивную динамику снижения доли природной ренты в ВВП более чем в полтора раза за последние 10 лет (в 2007 году показатель составлял 17\%). Однако, стоимостной и долевой размер природной ренты в сильной степени зависит от рыночных цен природных ресурсов, поэтому не может использоваться для динамических сопоставлений качества и структурных изменений в экономике. В свою очередь нами были рассчитаны исторические значения показателя качества экономики начиная с 2005 года, когда Росстатом был принят современный классификатор отраслей. Как выяннилось, его исторические значения в последние 13 лет колебались в узком диапазоне от 55\% до 62\%. С 2012 г. качественный показатель структуры экономики даже снизился на 3 процентных пункта. Описанная динамика подтверждает популярный тезис об отсутствии успехов в снижении сырьевой зависимости отечественной экономики.

Географические вариации показателя очень значительны - от $10 \%$ в Ненецком а.о., до 89\% в г. Севастополь. При этом пространственные закономерности изменения показателя близки к традиционным представлениям о сырьевых регионах. Пониженные значения «качества экономики» (от 10\% до 60\%) наблюдаются в большинстве восточных, азиатских регионов страны, а также в пределах известного своей тяжелой промышленностью Урала (см. рис. 2).

Вместе с тем, при анализе пространственной неравномерности показателя обнаруживаются менее известные феномены. Обращает на себя внимание выраженная сырьевая ориентации Ненецкого автономного округа, где наблюдаются наименьшие значения показателя (см. табл. 1), и Сахалинской 


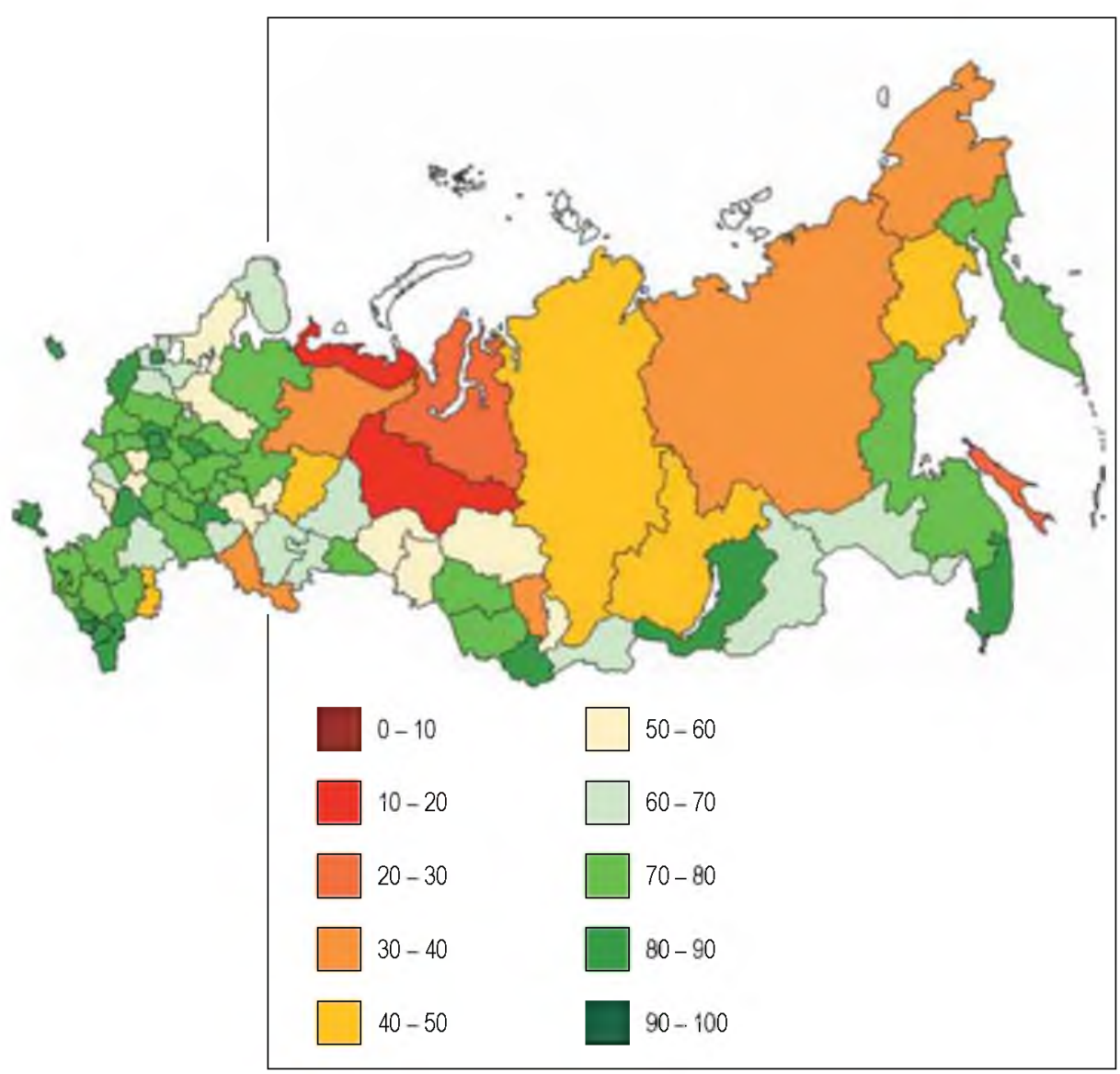

Рис. 2.

Индекс качества экономики, 2017 г. (\%).

Fig. 2. Economy Quality Index, 2017 (\%).

области, которые в популярной и научной прессе обычно не причисляются к сырьевым регионам. Отдельные промышленные регионы Урала, в частности Свердловская область и Челябинский край имеют относительно высокие показатели качества экономики (60-70\%), что связано с высоким уровнем развития обрабатывающих производств, а также сферы услуг в их административных центрах - городах-миллионерах. Напротив, существенно худшие в сравнении с ними значения показателя наблюдаются в Тульской, Липецкой, Белгородской и, особенно, в Оренбургской областях. Наилучшие значения показателя (85-89\%) фиксируются в пяти субъектах - трех городах федерального подчинения, а таюже Ивановской области и Чечне.

На региональном уровне наблюдались разнонаправленные изменения показателя. В целом, можно отметить тенденцию умеренного улучшения 
Таблица 1. РЕЙТИНГ СУБЪЕКТОВ С НАИХУДШИМИ ЗНАЧЕНИЯМИ ПОКАЗАТЕЛЯ «КАЧЕСТВО ЭКОНОМИКИ», 2017 г. (\%)

Table 1. Rating of subjects with the worst values of the indicator "quality of the economy", 2017 (\%)

\begin{tabular}{|c|c|c|}
\hline 1 & Ненецкий автономный округ & 10,7 \\
\hline 2 & Республика Саха (Якутия) & 35,6 \\
\hline 3 & Сахалинская область & 26,0 \\
\hline 4 & Ханты-Мансийский автономный округ - Югра & 17,8 \\
\hline 5 & Ямало-Ненецкий автономный округ & 21,3 \\
\hline
\end{tabular}

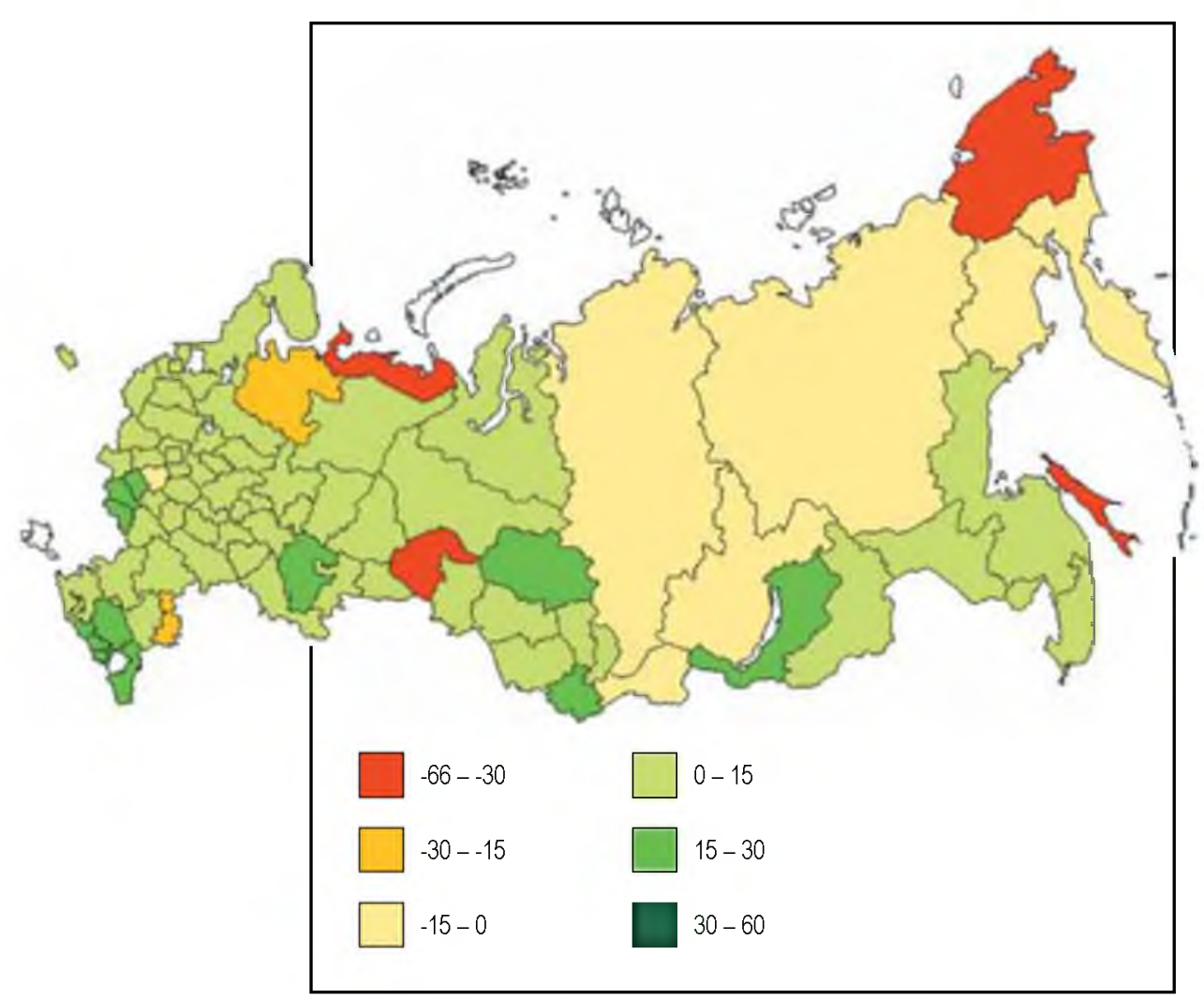

Рис. 3. 
(увеличения) показателя в большинстве регионов на величину порядка $10 \%$, что связано, в первую очередь с опережающим развитием сегмента услуг не сопряженного с эксплуатацией природных ресурсов и ущербом окружающей среде. Однако, на этом фоне большее внимание обращает резкое (-30\% и более) снижение показателя в ряде регионов, где были запущены масштабные проекты по добыче минеральных ресурсов - в первую очередь это Сахалинская область и Ненецкий а.о., где были реализованы проекты извлечения нефти и газа на шельфе. В пределах Чукотском а.о. развитие экономики почти целиком оказалось связано с запуском новых проектов добычи рудных ископаемых, а существенное ухудшение показателя в Астраханской и Архангельской области оказалось связано с запуском проектов по добыче нефти и газа.

\section{Количественная оценка.}

Валовый региональный продукт - количественная мера производства товаров и услуг, - в среднем на одного жителя России в 2017 году составил 510 тыс. рублей в текущих ценах [11]. Этот показатель быстро рос в период с 1999 по 2007 г., однако, с 2012 года наблюдается его стагнация в области максимальных значений (см. рис. 3 ).

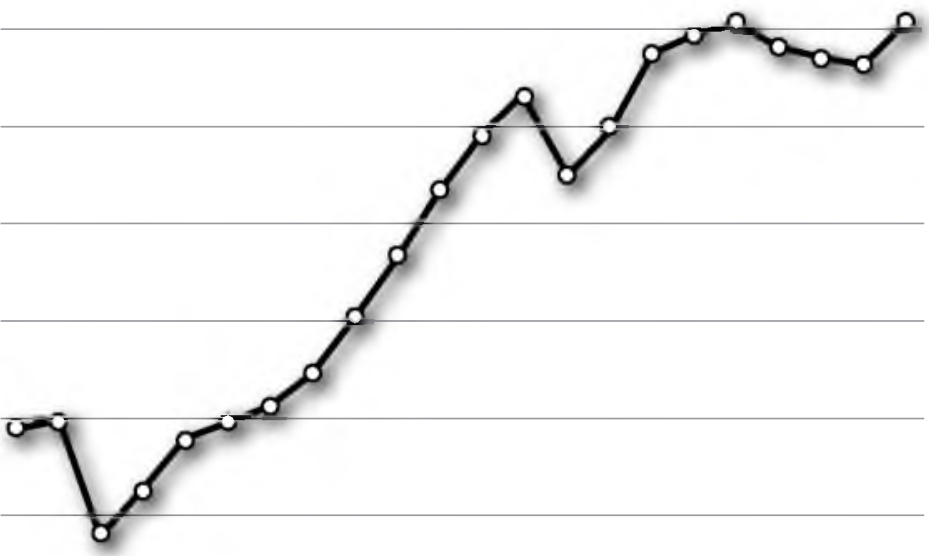

500

0

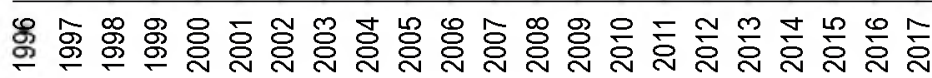

Рис. 3.

\section{ВРП на душу населения в среднем по России}

(тыс. руб. в ценах 2012 г.)

Fig. 3. Value Regional Product Per Capita Average For Russia (2012 constant 000 rubles). 
Географические различия в величине душевого ВРП в России весьма велики. Традиционными аутсайдерами по величине этого показателя являются Республики Чечня и Ингушетия (115 и 125 тыс. руб. на человека в год в текущих ценах, соответственно). Немногим выше эти показатели были в Кабардино-Балкарии и Карачаево-Черкесии (160 тыс. руб.). Лидирующие позиции по величине ВРП традиционно удерживают малозаселенные регионы с активной нефте- и газодобычей - Ханты-Мансийский а.о. (2,1 млн руб. на человека в год), Ямало-Ненецкий а.о. (4,6 млн руб.) и Ненецкий а.o. (6,3 млн). Таким образом лидирующий и отстающий субъект отличались по размеру душевого ВРП более чем в 50 раз (!). Если в последних его значения находятся на уровне наиболее богатых стран мира (Норвегия, Швейцария), то в Чечне значения показатель аналогичны таким странам как Камерун, Пакистан, Йемен.

К регионам с высоким уровнем ВРП в 2017 году можно было отнести 7 из 85 субъектов Российской Федерации (см. рис. 4). Явно выражен «ресурсный» характер их благосостояния. Шесть из упомянутых семи регионов известны своей специализацией на добыче полезных ископаемых: нефти и газа (ЯНАО, ХМАО, Ненецкий АО, Сахалинская обл., Ненецкий а.о.), рудных полезных ископаемых, преимущественно золота (Чукотский а.о., Магаданская обл.). Единственным исключением в данном списке остается г. Москва, где высокий ВРП является главным образом следствием выполнения функций административного и экономического центра страны.

Среди оставшихся территорий относительно высоким уровнем ВРП выделяются регионы с развитой промышленностью и крупными городскими центрами. Часть из этих субъектов расположена в пределах Уральского ФО - Пермский край, Свердловская область, Татарстан, Башкортостан, Повышенными значениями ВРП в пределах ЦФО отличаются также Санкт-Петербург, а также регионы окружающие два крупнейших мегаполиса - Московская и Ленинградская области и, кроме того Белгородская область успехи в развитии которой традиционно связываются с эффективной деятельностью региональной администрации. Повышения значения показателя также наблюдаются в Мурманской области, Республике Коми, в Тюменской области, в Красноярском крае и на Камчатке, где их также можно связать с эффектом от эксплуатации и первичной переработки наиболее прибыльных природных ресурсов (апатиты, рудные полезные ископаемые и нефть, рыбные ресурсы).

Пространственная локализация высоких показателей ВРП в России по сути определяются двумя факторами - возможностью по эксплуатации природной ренты и близостью к крупнейшим мегаполисам и административным центрам. Число факторов, с которыми связана неблагоприятная экономическая обстановка намного больше, низкими показателями душевого ВРП характеризуется несколько разнородных групп регионов. 


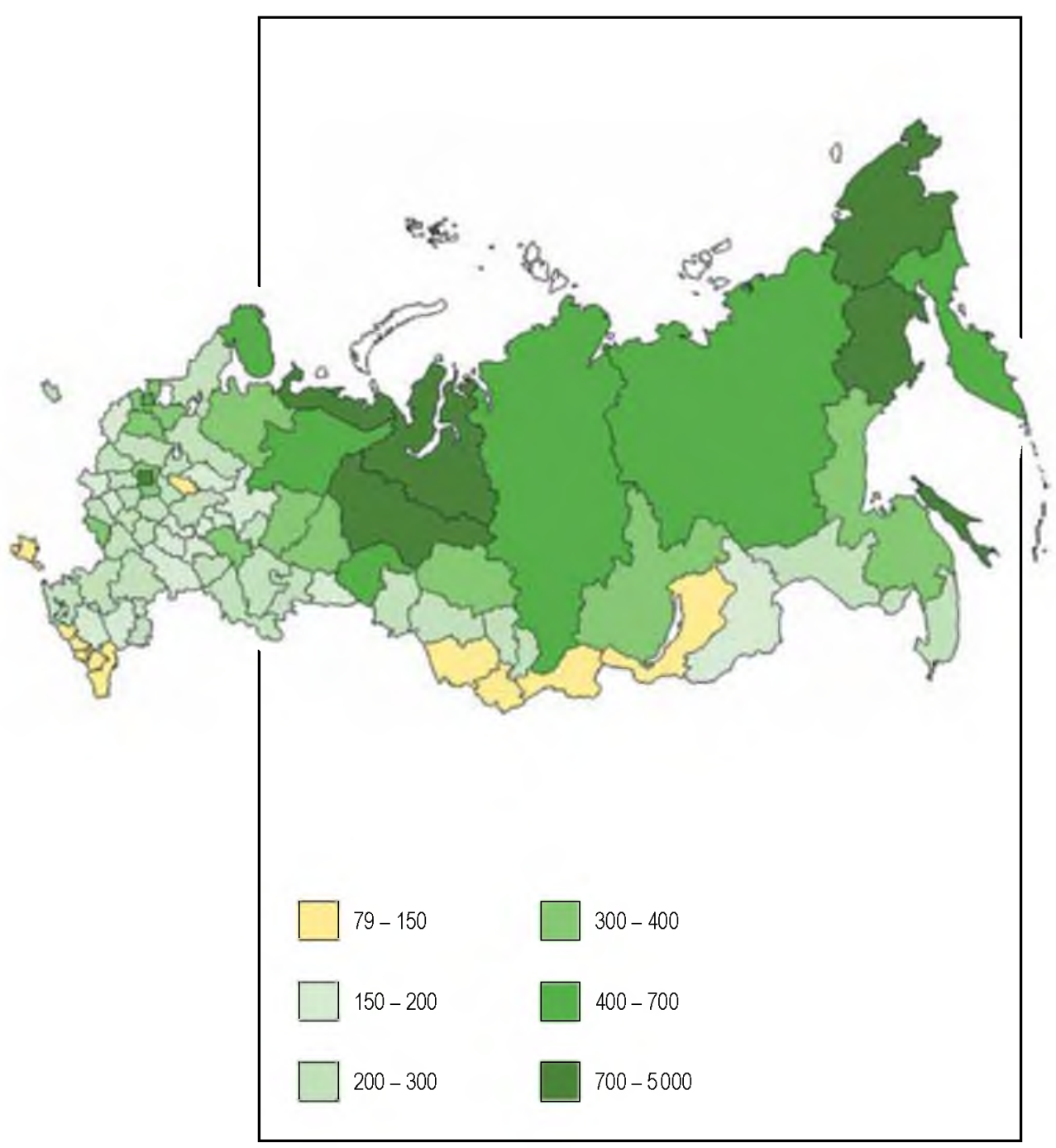

Pис. 4.

ВРП на душу населения по регионам России (тыс. руб. в ценах 2012 г.).

Fig. 4. Regional Product Per Capita For Russian Regions (2012 constant 000 rubles).

Во-первых, к их числу относится большинство т.н. национальных окраин, -- регионы, в национальном составе преобладают этнические меньшинства с доминирующим традишионном укладом жизни, и, при этом отсутствуют прибыльные, активно эксплуатируемые природные ресурсы (национальные республики Сев. Кавказа и Калмыкия, национальные образования южной части Сибири и Дальнего Востока). 
Вторая группа территорий - географические лакуны, территории, удаленные от основных центров экономической деятельности, крупных городов и ключевых транспортных магистралей). Помимо своего «неудобного» географического положения, эти территории как правило, отличаются высокой долей сельского населения и аграрного сектора. К числу таких регионов относятся Алтайский край, Еврейская а.о., Курганская область.

Третью, самую малочисленную группу образуют депрессивнье территории, где низкий ВРП является сравнительно новым по историческим меркам явлением и связан с конъюнктурным или более долгосрочным упадком основной для этих регионов отрасли специализации. Наиболее яркий пример такого рода - Ивановская область, отличавшаяся в дореволюционные и советские времена развитой легкой промышленностью, которая в рыночных условиях оказалась неконкурентоспособна и многократно снизила объемы выпуска за 90-е годы.

Наконец, низкими значениями показателя отличается Крым и г. Севасmополь, где слабое развитие хозяйственной деятельности, по-видимому, является историческим явлением - связано с недоинвестированием этих периферийных территорий во время пребывания Украины и с отставанием этого государства от России по уровню социально-экономического развития.

Особый интерес представляет динамика изменения регионального ВРП. Так, за десять лет - с 2007 по 2017 г. в среднем по стране душевой ВРП в постоянных ценах возрос на $19 \%$, однако в региональном разрезе его динамика варьировала от $-17 \%$ в Ханты-Мансийском а.о. до $+133 \%$ в Магаданской области (см. рис. 5). Такие, экстремальные, наиболее сильные среди других регионов подвижки определялись динамикой развития ресурсного сектора (добыча нефти и газа, золота, соответственно). С этой точки зрения показательны разнонаправленные изменения показателя в Ханты-Мансийском а.о. и соседним с ним Ямало-Ненецком а.о. (в его пределах душевой ВРП за тот же период, напротив, вырос на $84 \%$ в постоянных ценах), которые четко отражают процесс смещения добывающей промышленности на север Западной Сибири. Ресурсный фактор (освоение новых месторождений, расширение добычи полезных ископаемых) также объясняет значительный рост ВРП Астраханской области и Якутии.

В целом картина изменения душевого ВРП остается довольно «пестрой» и не обнаруживает крупных пространственных закономерностей - во всех частях страны есть как лидирующие, так и отстающие по этому показателю регионы. Среди отдельных любопытных явлений можно отметить значительный рост душевого ВРП в Калужской области (+71\% в постоянных ценах), который связан с удачным проектом развития промышленных зон на севере региона. Обращает на себя внимание отрицательная динамика душевого ВРП в г.Москве, что, по-видимому, связано с отрицательной 


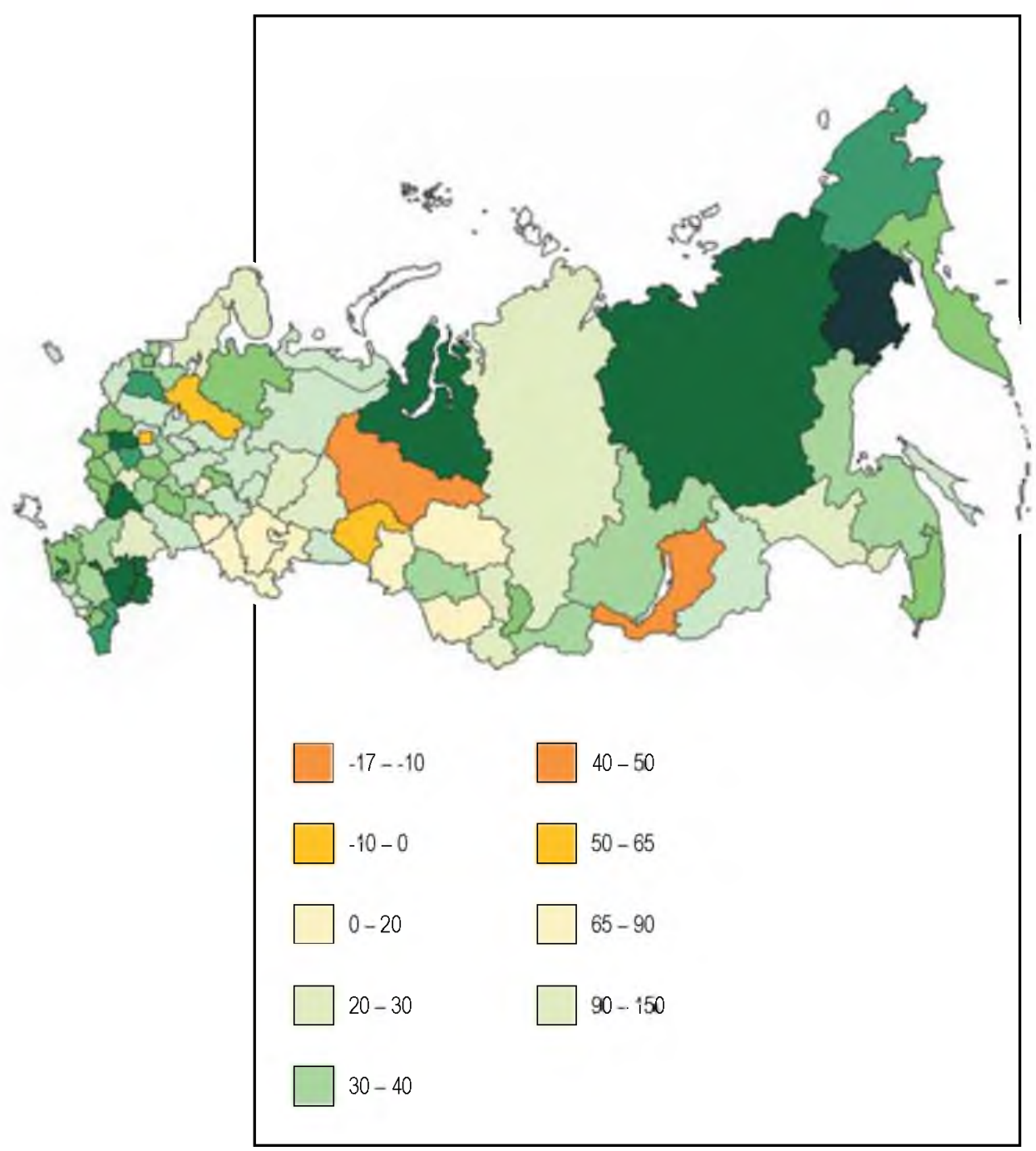

Рис. 5.

Изменение ВРП на душу населения в регионах России, 2017 г. к 2007 г. в постоянных ценах (\%).

Fig. 5. Changes of Per Capita Regional Product For Russian Regions, 2017/2007 constant prices (\%).

динамикой денежных доходов населения на крупнейшем потребительском рынке страны.

В последние годы существенных изменений душевого ВРП на региональном уровне не происходит - наблюдается относительно слабая разнонаправленная динамика показателя без четких пространственных закономерностей (см. рис. 6) за единственным исключением. Наивысшие показатели 


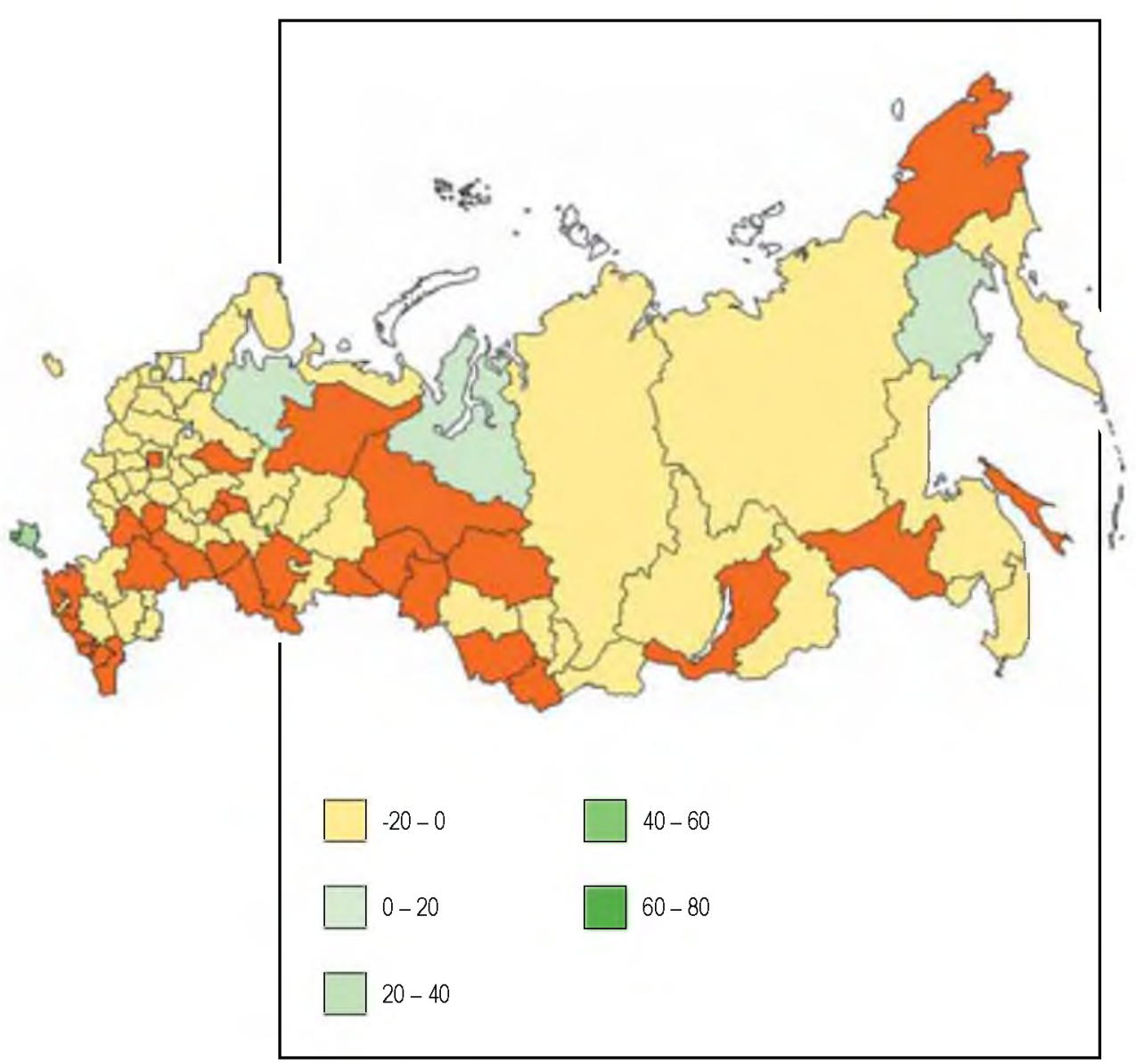

Рис. 6.

Изменение ВРП на душу населения в регионах России, 2017 г. к 2014 г. в постоянных ценах (\%).

Fig. 6. Changes of Per Capita Regional Product For Russian Regions, 2017/2014 constant prices (\%).

прироста ВРП наблюдаются в перешедших из состава Украины Республике Крым (+53\%) и г. Севастополь (+73\%). Такая особенность определяется последствиями активного притока частных инвестиций в рекреационный сектор полуострова и резким увеличением региональных трансфертов по сравнению с теми средствами которые выделялись этому региону во время его пребывания в составе Украины. 


\section{Выводы}

«Качество» Российской экономики остается низким - за последние 15 лет не наблюдается существенных структурных подвижек и снижения роли сырьевого сектора. Одним из государственных приоритетов в последнее десятилетие обозначен «Поворот на восток» -- опережающее развитие восточной части страны и рост экспортных поставок в этом направлении. Во многих субъектах относящихся к этому макрорегиону действительно наблюдается улучшение экономических показателей и рост регионального ВРП, который в целом несколько превосходит в последнее десять лет показатели регионов Европейской России. Однако, как показывает проведенный анализ, эта позитивная тенденция в основном связана с освоением сырьевых ресурсов, - вес секторов экономики связанных с эксплуатацией природной ренты с 2005 по 2017 г. в большинстве регионов востока страны возрос. Значимыми исключениями из этой тенденции является Забайкальский край и Республика Алтай, где улучшение качественной структуры экономики связано с опережающим развитием рекреационного сектора и сопутствующих отраслей.

После периода быстрого роста в 1998 - 2007 и 2010-2011 гг. количественные показатели экономического развития регионов стагнируют и остаются почти неизменными. На длинном интервале времени - с 2007 по 2017 г. наибольший прирост регионального ВРП демонстрируют регионы расширяющие добычу полезных ископаемых, что подчеркивает сырьевой характер экономики и в целом неудачный результат проектов опережающего экономического развития за счет роста обрабатывающей промышленности и наукоемких секторов экономики. В то же время значительное увеличение ключевого экономического показателя в абсолютном и относительном выражении сумели продемонстрировать отдельные регионы (Белгородская, Калужская области), где местные власти добились успехов в привлечении частных инвестиций в развитие промышленного сектора, за счет мер административной поддержки и развития инфраструктуры.

Рукопись поступила в редакцию 03.06 .19 г., принята к публикации 02.09.19 г. 


\section{БИБЛИОГРАФИЧЕСКИЙ список}

1. Развитие и международное сотрудничество: проблемы окружающей среды / Генеральная ассамблея $\mathrm{OOH}$. Доклад всемирной комиссии по вопросам окружающей среды и развития. Записка Генерального секретаря. Нью-Йорк, 4 августа 1987 года. С. 412.

2. Указ Президента Российской Федерации N 440 «О Концепции перехода Российской Федерации к устойчивому развитию» Москва, Кремль, 1 апреля 1996 года. [Электронный ресурс] Официальный интернет-портал правовой информации URL: http://pravo.gov. ru/proxy/ips/?docbody $=\&$ firstDoc $=1 \&$ lastDoc $=1 \&$ nd $=102040449$

3. Показатели устойчивого развития: структура и методология. Пер. с англ. Тюмень: Изд-во ИПОС СО РАН, 2000. 359 с.

4. Индикаторы устойчивого развития России (эколого-экономические аспекты) / под ред. С.Н. Бобылева, П.А. Макеенко. М.: ЦПРП, 2001. $220 \mathrm{c}$.

5. Arrow, K. J.; Dasgupta, P.; Goulder, L.; Daily, G.; Ehrlich, P. R.; Heal, G. M.; Levin, S.; Maler, K-G.; Schneider, S.; Starrett, D. A.; Walker, B. (2004). "Are we consuming too much?". Journal of Economic Perspectives. 18 (3): 147-172.

6. Brown, L. R. (2011). World on the Edge. Earth Policy Institute. Norton. ISBN 978-0-393-08029-2.

7. Рубанов И.Н. Расчет индекса устойчивого развития регионов России // Научный сборник «Региональный вестник Востока». №2(62), 2014. C. 58-69.

8. World Development Indicators [Электронный pecypc]. База данных World Bank https://datacatalog.worldbank.org/dataset/worlddevelopment-indicators

9. Витрина статистических данных [Электронный ресурс]. База данных Росстата URL: https://showdata.gks.ru/finder/

10. Рубанов И.Н. Описание методики разработки интегральных индикаторов для оценки свойств пространственных объектов и анализ типовых ошибок исследований (на примере индикаторов устойчивого развития и регионов России) / ИнтерКарто. ИнтерГИС. Геоинформационное обеспечение устойчивого развития территорий: Материалы Междунар. конф. М.: Изд-во Московского ун-та, 2019. С. 5-17.

11. Единая межведомственная информационная система [Электронный ресурс]. Государственная статистика EMИCC URL: https://mww.fedstat. ru

12. United Nations Development Programme. Human Development Report. — New York: Palgrave Macmillan, 2014. 


\section{References}

1. Development and International Economic Co-Operation: Environment / UN General Assembly. Report of the World Commission on Environment and Development: Our Common Future. Secretary General Report. N-Y, 4 August 1987. P. 374.

2. Decree of President of Russian Federation N 440 «About conception of Russian Federation transition to Sustainable Development». Moscow, Kremlin, 1 April 1996. [Internet]. Oficial'nyj internet-portal pravovoj informacii URL: http://pravo.gov.ru/proxy/ips/?docbody=\&f irstDoc $=1$ \&lastDoc $=1$ \&nd $=102040449$

3. Pokazateli ustojchivogo razvitiya: struktura i metodologiya. Translated from English. Tumen: Izd-vo IPOS SO RAN, 2000. P. 359.

4. Indikatory ustojchivogo razvitiya Rossii (ekologo-ekonomicheskie aspekty). / Pod red. S.N. Bobyleva, P.A. Makeenko. M., 2001. P. 220.

5. Arrow, K. J.; Dasgupta, P.; Goulder, L.; Daily, G.; Ehrlich, P. R.; Heal, G. M.; Levin, S.; Maler, K-G.; Schneider, S.; Starrett, D. A.; Walker, B. (2004). "Are we consuming too much?". Journal of Economic Perspectives. 18 (3): 147-172.

6. Brown, L. R. (2011). World on the Edge. Earth Policy Institute. Norton. ISBN 978-0-393-08029-2.

7. Rubanov I.N. Sustainability index calculation for Russian regions // Collection of scientific works "Regional'nyj vestnik Vostoka", №2(62), 2014. Pp. 58-69.

8. World Development Indicators [Internet]. World Bank database URL:https://datacatalog.worldbank. org/dataset/world-development-indicators

9. Vitrina statisticheskih dannyh [Internet]. Rosstat database URL: https://showdata.gks.ru/finder/

10. Rubanov I. N. Description of the methodology for the development of integrated indicators for assessing the properties of spatial objects and analysis of typical research errors (for example, indicators of sustainable development and regions of Russia) / InterCarto. Intergis. Geoinformation support of sustainable development of territories: Materials of Intern. Conf. Moscow: publishing house of Moscow University, 2019. C. 5-17.

11. Edinaya mezhvedomstvennaya informacionno-statisticheskaya sistema. EMISS - Gosudarstvennaya statistika. [Internet] URL: https://www.fedstat.ru

12. United Nations Development Programme. Human Development Report. New York: Palgrave Macmillan, 2014. 


\section{OБ АBTOPAX}

Рубанов И.Н. старший научный сотрудник Географического фракультета МГУ им. М.В. Ломоносова.

E-mail: rubanovin@yandex.ru.

Нокелайнен Т.С. ведущий научный сотрудник Географического фракультета МГУ им. М.В. Ломоносова.

E-mail: nokelta@rambler.ru

Калинкин И.В., научный сотрудник Географического ффакультета МГУ им. М.В.Ломоносова.

E-mail: ikl@geogr.msu.su.

Игонин Александр Иванович, кандидат географических наук, младший научный сотрудник Лаборатории комплексного картографирования, Географический факультет, Московский государственный университет им. М.В. Ломоносова.

ScopusID: 53863614000, Researcher ID: M-2916-2015.

Телефон: +7(495) 939-23-54 E-mail: geoigonin@gmail.com

\section{About the authors}

Rubanov I.N. Senior Researcher Geography Department of MSU by M.V. Lomonosov.

E-mail: rubanovin@yandex.ru.

Nokelaynen T.S. Leading Researcher Geography Department of MSU by M.V. Lomonosov.

E-mail: rubanovin@yandex.ru.

Kalinkin I.V. Researcher Geography Department of MSU by M.V.Lomonosov. E-mail: rubanovin@yandex.ru.

Igonin Aleksandr Ivanovich, Candidate of Geographical Sciences, Junior researcher of the Integrated Mapping Laboratory, Faculty of Geography, Lomonosov Moscow State University.

ScopusID: 53863614000, Researcher ID: M-2916-2015.

Phone: +7(495)939-23-54. E-mail: geoigonin@gmail.com 